\title{
Socio-Economic Consequences of Mental Distress: Quantifying the Impact of Self-Reported Mental Distress on the Days of Incapacity to Work and Medical Costs in the Following 2 years: A Longitudinal Study in Germany
}

\author{
Gerhard Müller ( $\nabla$ gerhard.mueller@bw.aok.de ) \\ AOK Baden-Württemberg https://orcid.org/0000-0001-6596-4511 \\ Manuela Bombana \\ AOK Baden-Wuerttemberg \\ Monika Heinzel-Gutenbrenner \\ Akademi IImu Statistik: Politeknik Statistika STIS \\ Nikolaus Kleindienst \\ Zentralinstitut fur Seelische Gesundheit \\ Martin Bohus \\ Zentralinstitut fur Seelische Gesundheit \\ Lisa Lyssenko \\ PH Freiburg: Padagogische Hochschule Freiburg \\ Ruben Vonderlin \\ Zentralinstitut fur Seelische Gesundheit
}

Research article

Keywords: mental distress, incapacity for work, longitudinal study, prevention and health promotion, presenteeism

Posted Date: December 8th, 2020

DOI: https://doi.org/10.21203/rs.3.rs-122526/v1

License: (c) (i) This work is licensed under a Creative Commons Attribution 4.0 International License. Read Full License

Version of Record: A version of this preprint was published at BMC Public Health on March 31st, 2021. See the published version at https://doi.org/10.1186/s12889-021-10637-8. 


\section{Abstract}

Background: Mental disorders are related to high individual suffering and significant socio-economic burdens. However, it remains unclear to what extent selfreported mental distress is related to individuals' days of incapacity to work and their medical costs. This study aims to investigate the impact of self-reported mental distress for specific and non-specific days of incapacity to work and specific and non-specific medical costs over a two-year span.

Method: Within a longitudinal research design, 2,287 study participants' mental distress was assessed using the Hospital Anxiety and Depression Scale (HADS). Days of incapacity to work and medical costs were retrieved from a German health insurance's routine data during the following two-year period.

Results: Current mental distress was found to be significantly related to the number of specific days absent from work and medical costs. Compared to participants classified as no cases by the HADS (2.6 days), severe case participants showed 27.3-times as many specific days of incapacity to work in the first year (72 days) and 10.3-times as many days in the second year (44 days), and resulted in 11.4-times more medical costs in the first year (2272 EUR) and 6.2times more in the second year (1319 EUR). The relationship of mental distress to non-specific days of incapacity to work and non-specific medical costs is also significant, but mainly driven from specific absent days and specific medical costs. Our results also indicate that the prevalence of presenteeism is considerably high: $42 \%$ of individuals continued to go to work despite severe mental distress.

Conclusions: Our results show that self-reported mental distress, assessed by the HADS, is highly related to the days of incapacity to work and medical costs in the two-year period. Reducing mental distress by improving preventive structures for at-risk populations and increasing access to evidence-based treatments for individuals with mental disorders might, therefore, pay for itself and could help to reduce public costs.

\section{Background}

Mental disorders are related to high individual suffering and a significantly reduced quality of life for those affected [1,2]. In addition, they are related to significant socio-economic burdens worldwide [3-6]. Depression and anxiety disorders are ranked third and eighth among all diseases regarding the most years lived with disability (DALY) worldwide [5, 7]. More than one in six people across industrialized countries and the world is suffering from a current mental disorder (18\% Germany, $17.3 \%$ the EU, $18.9 \%$ the US, and 17.6\% worldwide) [8, 9]. According to current forecasts, the economic burden of mental disorders will continue to increase in the coming years. Accordingly, it has been assumed that direct and indirect medical costs due to mental illness will more than double between 2010 and 2030 (factor 2.4) and that the global loss of economic output (loss of working days) will amount to \$16.3 USD trillion during this period (2011-2030) [10, 11].

Therefore, recognizing and reducing mental stress are of central importance to society to reduce individual suffering and socio-economic burdens [12]. For doing so, individuals with mild or moderate mental distress should be given access to prevention services. In addition, individuals with severe mental distress or even mental illness should be given rapid access to specific treatments and professional help. However, to date, mental distress or even mental illness are often detected and treated too late or not at all. Only about one in five mentally ill people seek medical treatment (18.9\% as 12-month prevalence) [13]. The treatment gap for mental disorders is universally large across countries [14]. Over time, mild mental distress can turn into severe mental distress - with its consequences of duration of incapacity to work and sickness costs.

Creating a low-threshold and rapid access to professional help requires financial investment. At the same time, when considering the reduction of days of incapacity to work and productivity losses, it could save money. Results from the English Improving Access to Psychological Therapies (IAPT; e.g., [15]) service in the UK have shown that increasing access to psychological therapies would largely pay for itself by reducing other depression and anxiety-related public costs (e.g., medical costs and productivity loss) and increasing revenues (e.g., paying taxes; [16]). It has been suggested that mental health services from other countries might benefit from adopting this approach [17]. However, to the best of our knowledge, a detailed analysis of the socio-economic consequences of mental distress from other European countries in the general population is still lacking. This analysis is important in estimating the potential amount of money that could be saved by effective treatments and invested in improving services. Health insurers, politicians, employers, and other health care decision-makers should, therefore, be informed about the financial consequences of increased mental distress when thinking about implementing and improving preventive and curative structures to maintain and restore mental health.

\section{Aim of the study}

This study aims to examine the impact of different degrees of self-reported mental distress (no distress, mild distress, moderate distress and severe distress), assessed by the HADS, on the number of specific (due to mental disorder) and non-specific (due to any diagnosis) days of incapacity to work (DIW) as well as specific and non-specific medical costs in a two-year period in Germany.

\section{Method}

Data from a large health promotion intervention study were used, which were conducted in 2013 and 2014 in 43 locations in Southern Germany [18-20]. The study has been registered in the German Register of Clinical Trials (DRKS) and was approved by the Ethics Review Committee at the University of Heidelberg, Germany (Study Registration: DRKS00006216). For this study, data collected in a longitudinal section were evaluated. At the beginning of the study (t0), the mental distress and the sample's socio-demographic data were collected. The DIW data were analyzed with a latency of one and two years, respectively, starting after t0.

\section{Sample}


A total of 34,207 policyholders of a large German health insurance company were contacted, 5,549 of whom declared their willingness to participate in the study. This corresponds to a response rate of $16 \%$. The data could not be analyzed for 861 participants because (i) the questionnaire data was incomplete or DIW data was not available because of being insured with another health insurance company $(n=808)$, (ii) consent to participate in the study was withdrawn $(n=20)$, or (iii) the questionnaire was sent out twice $(n=23)$. The education variable "still in school" $(n=10)$ was excluded because the incomplete educational status could not be included in the ranking of the education factor. Of the remaining 4,688 insured persons, 1,329 insured persons were not included because they were not entitled to sickness benefits (e.g., pensioners, family insured persons, rehabilitates, voluntarily insured persons not entitled to sickness benefit), and 1,072 because they belonged to the experimental group in the initial study. Finally, a total sample of 2,287 study participants were included in the analyses. For details, see Lyssenko et al. [18].

\section{Assessments}

\section{Mental distress}

Cross-sectional mental distress was assessed with the Hospital Anxiety and Depression Scale (HADS) [21]. The HADS is a self-report questionnaire measuring anxiety and depressive symptoms with good psychometric properties [22]. The questionnaire consists of seven items for each of the two subscales. Total scores can be calculated for each subscale, ranging from 0 to 21 or an overall score for both subscales ranging from $0-42$, which can be interpreted as a global screener of mental distress [23]. Higher values in the subscales indicate more severe anxiety or depressive symptoms. Based on the values in one of the two subscales, the degree of mental distress can be differentiated as no distress (0-7), mild distress (8-10), moderate distress (11-15), and severe mental distress ( $\geq 16$ ) [24]. In addition, cut-off values are provided to distinguish between inconspicuous values and values requiring therapy. For the HADS, cut-off values apply to one of the two subscales of $\geq 8$ (values $\geq 11$ are considered conspicuous) $[25,26]$. Therefore, a need for therapy should be clarified by further procedures, even at a low level of mental distress. A meta-analytic consideration showed an averaged sensitivity of 0.82 and specificity of 0.74 when applying a cut-off point of 8 and an averaged sensitivity of 0.56 and specificity of 0.92 when applying a cut-off point of 11 across different clinical samples [27]. In our sample, the HADS showed good reliability, with a Cronbach's a of 0.91 .

\section{Days of incapacity to work}

The number of specific and non-specific DIW was selected from all study participants' routine health insurance data. As specific DIW, the days of incapacity to work due to mental illness were selected (i.e., ICD 10, F00-F99, "mental and behavioral disorders", and ICD 10, Z73, "problems with regard to difficulties in coping with life", including burn-out). As non-specific DIW, all days of incapacity to work due to any ICD 10 diagnosis were selected. Both specific and nonspecific DIW were retrieved cumulatively during the first and second year, starting on the day after the HADS assessment.

\section{Medical costs}

Direct specific and non-specific medical costs were retrieved from routine health insurance data for all study participants. The direct specific health care costs of the diagnostic main group "mental and behavioral disorders" (ICD 10, F00-F99) and "problems related to difficulties in coping with life (Z73 including accentuation of personality traits, being burnt out)" were determined for the cost fields of outpatient treatment, hospital (main diagnosis), and rehabilitation (admission diagnosis). The drug costs were composed of the costs for antidepressants (N06A), psycholeptics, and psychoanaleptics in combination (N06C), anxiolytics (N05B), and hypnotics and sedatives (N05C). The averaged direct specific and non-specific medical costs are available in Euro and were retrieved cumulatively during the first and second year, starting on the day after the HADS assessment.

\section{Socio-demographic data}

The socio-demographic characteristics of the sample age, gender, and employment status were retrieved from the routine health insurance data. The questionnaires also assessed education and marital status.

\section{Statistical analyses}

The DIW and the cost data represent a mixture of a discrete distribution with positive probability mass at zero (many participants do not have any DIW) and a continuous distribution for data $>0$ and represent a left-skewed distribution. This form of mixed distribution is known as the Tweedie or Poisson-gamma distribution $[28,29]$. Accordingly, a generalized linear model with a Tweedie distribution with log link function was calculated with mental distress (HADS) as an independent variable and the specific and non-specific DIW in the first and second year after the HADS assessment as dependent variables. Since prior studies have shown an effect of socio-demographic variables on DIW [30-32], we include our sample's socio-demographic variables as control variables in the model (age, gender, education, and relationship and employment status). The analyses were performed with SPSS 26.

\section{Results}

The sample of 2,287 participants consisted of $89 \%$ women and averaged 46.1 years of age $(S D=10.4)$. Most $(72.4 \%)$ of the study participants were married. The percentage of participants holding an A-Level degree was $25.7 \%$, whereas $2.5 \%$ had no school-leaving certificate. A small group of participants (0.5\%) became unemployed by losing their job during the study period. Regarding mental distress, $47.6 \%$ of study participants were classified as no case, $24.1 \%$ were classified as a mild case, $23.5 \%$ were classified as moderate cases, and $4.7 \%$ were classified as severe cases, by applying the proposed cut-off values to their HADS scores. Socio-demographics of the sample are depicted in Table 1.

With $80 \%$ of all specific DIW due to mental illnesses, the diagnostic groups, affective disorders (42\%, e.g., depression) and neurotic, stress, and somatoform disorders (38\%, e.g., anxiety disorders) dominate in the sample. None of the other diagnostic groups from the "mental and behavioral disorders" showed a 
proportion above $9 \%$ (i.e., $8 \%$ substance-related disorders, $7 \%$ personality disorders, $3 \%$ schizophrenia spectrum disorders, $2 \%$ behavioral syndromes associated with physiological disturbances and physical factors [e.g., eating disorders], 1\% mental disorders due to known physiological conditions [e.g., dementia]).

However, $79.6 \%$ of our sample had no specific DIW in the two years that followed the HADS testing. Based on the sample's HADS scores, the percentage of participants who did not have any specific DIW was $89 \%$ for no cases, $82 \%$ for mild cases, $66 \%$ for moderate cases, and $42 \%$ for severe cases. Regarding nonspecific DIW, $21 \%$ of our sample had no non-specific DIW in the following two years. Based on the sample's HADS scores, the percentage of participants who did not have any non-specific DIW was $27 \%$ for no cases, $20 \%$ for mild cases, $13 \%$ for moderate cases, and still $8 \%$ for severe cases.

Regarding specific (non-specific) medical costs, the proportion without any costs depending on the HADS scores was $51.1 \%$ ( $1.0 \%$ ) for no cases, $38.9 \%$ (0.4\%) for mild cases, $19.9 \%(0.0 \%)$ for moderate cases, and $8.3 \%$ (0.9\%) for severe cases.

\section{Impact of socio-demographic variables}

\section{Gender}

Gender revealed no significant differences in non-specific and specific DIW in the first and second years (Tables 2 and 3). Accordingly, no differences in nonspecific medical costs were obtained between male and female participants (Table 4). However, specific medical costs were significantly increased for female participants in the second year (Table 5). Compared to men, female participants showed 1.2-times as many specific medical costs $\left(\chi^{2}[1]=2.60, p=.107\right)$ in the first year and 1.4-times as many specific medical costs $\left(\chi^{2}[1]=8.51, p=.004\right)$ in the second year.

\section{Age}

Compared to 18-33-year-old participants, older participants showed significantly increased non-specific DIW in the first year $\left(\chi^{2}[2]=22.54, p<.001\right.$, factor 1.2 to 1.5 ) and the second year $\left(\chi^{2}[2]=31.86, p<.001,1.1\right.$ to 1.5$)$. This increase of non-specific DIW was not driven by higher specific DIW (first year: $\chi^{2}[2]=2.31$, $p=.315$; second year: $\left.\chi^{2}[2]=2.23, p=.328\right)$. Accordingly, older participants showed significantly higher non-specific medical costs in the first year $\left(\chi^{2}[2]\right)=$ $11.68, p=.003)$ and second year $\left(\chi^{2}[2]=26.83, p<.001\right)$, but no significant differences in specific medical costs.

\section{Marital status}

Marital status revealed no significant differences in non-specific and specific DIW in the first or second years. Accordingly, no differences in non-specific medical costs were obtained between married and unmarried participants. The specific medical costs, however, were significantly increased in unmarried participants both in the first year $\left(\chi^{2}[1]=30.56, p<.001\right.$, factor 1.5$)$ and the second year $\left(\chi^{2}[1]=12.51, p<.001\right.$, factor 1.3$)$.

\section{Education}

Lower educated participants showed a significant increase in non-specific DIW. Compared to participants holding an A-Level degree, lower educated participants showed 1.2 to 2.2 as many non-specific DIW in the first $\left(\chi^{2}[3]=33.59, p<.001\right)$ and in the second year $\left(\chi^{2}[3]=54.60, p<.001\right)$. The number of specific DIW was also increased for lower educated participants, however, this only yielding significance in the second year. Lower educated participants showed in the first year 1.2 to 2.0 as many specific DIW $\left(\chi^{2}[3]=3.46, p=.326\right)$ and in the second year 1.4 to 3.3 as many specific DIW $\left(\chi^{2}[3]=11.22, p=.011\right)$ Regarding the medical costs, no differences were obtained on non-specific costs in the first year, but an increase was shown in non-specific medical costs for lower educated participants in the second year $\left(\chi^{2}[3]=43.12, p<.001\right)$. An opposite pattern was found concerning specific costs. Here, lower educated participants showed increased costs in the first year $\left(\chi^{2}[3]=14.56, p=.002\right)$ but not in the second year.

\section{Employment Status}

Employment status revealed no significant differences in non-specific and specific DIW in the first and second years. However, the non-specific costs of unemployed participants were significantly increased. Compared to employed participants, unemployed participants showed 2.0-times as many non-specific medical costs $\left(\chi^{2}[1]=8.99, p<.003\right)$ in the first year and 1.7-times as many non-specific medical costs $\left(\chi^{2}[1]=4.07, p=.044\right)$ in the second year. Specific medical costs of unemployed participants were descriptively increased (1.3 to 1.5), but this was not significant.

\section{Impact of self-reported mental distress}

The impact of HADS severity scores on specific and non-specific DIW and medical costs in the first and second years after HADS assessment is depicted in Figure 1.

\section{Days of Incapacity to Work}

Mental distress, as measured with the HADS at t0, showed a significant effect on the number of non-specific DIW in the first year $\left(\chi^{2}[3]=320.78, p<.001\right.$; see Table 2$)$ and the second year $\left(\chi^{2}[3]=195.17, p<.001\right)$. The number of non-specific DIW increased continuously with the degree of mental distress. While participants classified as no cases averaged 15.8 non-specific DIW in the first year (13.1 in the second year), mild case participants averaged 1.6 (1.5) times as many non-specific DIW ( $M=25.8$ days in the first year and $M=19.1$ days in the second year), moderate case participants averaged 2.8 (2.3) times as many non-specific DIW ( $M=44.7$ days in the first year and $M=30.6$ days in the second year), and severe case participants averaged 5.1 (3.7) times as many nonspecific DIW ( $M=81.4$ days in the first year and 48.9 days in the second year). 
This increase of non-specific DIW was mainly driven by an increase of specific DIW in the first year $\left(\chi^{2}[3]=196.98, p<.001\right)$ and the second year $\left(\chi^{2}[3]=\right.$ $106.21, p<.001$; see Table 3): While participants, classified as no cases averaged 2.6 specific DIW in the first year (4.3 in the second year), mild case participants averaged 2.8 (1.5) times as many specific DIW ( $M=7.4$ days in the first and $M=6.2$ days in the second year), moderate case participants averaged 10.5 (4.7) times as many specific DIW ( $M=27.5$ days in the first and $M=20.1$ days in the second year), and severe case participants averaged 27.3 (10.3) times as many specific DIW ( $M=71.5$ days in the first and $M=43.9$ days in the second year).

The increases of DIW in the first and second years were obtained on both the anxiety and depression subscales (all $p$ values $<.001$ ).

\section{Medical Costs}

The increase of DIW depending on mental distress was also reflected in higher non-specific medical costs in the first year $\left(\chi^{2}[3]=164.41, p<.001 ;\right.$ see Table 4) and the second year $\left(\chi^{2}[3]=110.45, p<.001\right)$. Again, the number of non-specific medical costs increased continuously according to the degree of mental distress: While participants classified as no cases averaged 2031 EUR non-specific medical costs in the first year (2260 EUR in the second year), mild case participants had $1.2(1.2)$ times as many non-specific medical costs $(M=2330$ EUR in the first year and $M=2635$ EUR in the second year); moderate case participants had $1.5(1.5)$ times as many non-specific medical costs $(M=3048$ EUR in the first and $M=3292$ EUR in the second year); and severe case participants had 2.7 (1.9) times as many non-specific medical costs $(M=5544$ EUR in the first and $M=5181$ EUR in the second year).

The increase of non-specific medical costs was again mainly driven by an increase of specific medical costs in the first year $\left(\chi^{2}[3]=496.56, p<0.001\right.$; see Table 5) and the second year $\left(\chi^{2}[3]=309.45, p<.001\right)$ : While participants classified as no cases averaged 199 EUR specific medical costs in the first year $(213$ EUR in the second year), mild case participants had $2.2(1.3)$ times as many specific medical costs $(M=434$ EUR in the first and $M=272$ EUR in the second year); moderate case participants had 4.7 (3.1) times as many specific medical costs ( $M=941$ EUR in the first and $M=661$ EUR in the second year); and severe case participants had 11.4 (6.2) times as many specific medical costs ( $M=2272$ EUR in the first and 1319 EUR in the second year).

The increases in medical costs in the first and second years were obtained on both the anxiety and depression subscales (all $p$ values $<.001$ ).

\section{Discussion}

This study aimed to examine the impact of self-reported mental distress, assessed by the HADS, on the number of specific and non-specific DIW and medical costs in the two years following the testing. To address this aim, we conducted a longitudinal study, in which the HADS scores of 2,287 participants were used to predict their specific and non-specific DIW and medical costs in the first and second years after HADS assessment.

Our results revealed that self-reported mental distress (HADS scores) was significantly related to the number of non-specific DIW in the first and second years. Accordingly, the number of non-specific DIW increased continuously based on the level of mental distress. Compared to the reference group classified as no cases, severe cases had 5.1-times as many non-specific DIW in the first year and 3.7-times as many non-specific DIW in the second year. Not surprisingly, the increase of non-specific DIW was mainly driven by a significant increase of specific DIW. Compared to the no cases, severe cases showed 27.3-times as many specific DIW in the first year and 10.3-times as many specific DIW in the second year.

These results demonstrate that mental distress impacts a person's life for several years by predicting their sickness absence rates even two years later. This increased sickness absence rate might be, in turn, related to a generally reduced social and occupational functioning levels and reduced well-being of individuals [33]. Furthermore, mental distress appears to be a central challenge for employers in terms of productivity loss. The financial consequences of specific DIW due to production loss can be calculated by multiplying the specific DIW by average income. Regarding average costs due to production loss in 2014 of 105 EUR per DIW [34], the averaged additional costs for an employee under severe mental distress due to absenteeism alone amount to 7,230 EUR in the first years and 4,163 EUR in the second year, compared to an employee without mental distress. According to prior empirical findings, the additional costs due to presenteeism can be estimated to be two to three times higher [31]. Our results revealed that $66 \%$ of participants classified as moderate cases and $42 \%$ of participants classified as severe cases, did not have any specific DIW in the two-year period that was analyzed. These results indicate that the percentage of people who go to work despite severe mental distress might be considerably high and illustrate the importance and spread of presenteeism. Given this high prevalence of presenteeism and the assumed adverse mental health outcomes, future studies should characterize this sub-sample's psychological and sociodemographic characteristics to better understand the risk factors for presenteeism. By doing so, a distinction should be made between whether work is perceived as a resource and thus contributes to the stabilization of mental health, or as a stressor that leads to the maintenance of high mental distress.

Both the anxiety and depression subscales of the HADS were predictive for specific and unspecific DIW. This is not surprising since $80 \%$ of all specific DIW in our sample were caused by the diagnostic groups' affective disorders (42\%, e.g., depression) and neurotic, stress and somatoform disorders (38\%, e.g., anxiety disorders). This roughly corresponds to results from other studies in Germany, in which $88.6 \%$ of all specific DIW resulted from affective (41.4\%) or neurotic, stress, and somatoform disorders (47.2\%) [32]. Accordingly, it seems plausible that both the anxiety and depression subscale of the HADS predicted the number of specific DIW in our analyses. However, the impact of both HADS subscales for non-specific DIW is in contrast to the results of Schneider et al. [30], in which only the anxiety symptoms, but not the depressive symptoms, were found to be a significant predictor of the duration of absences due to non-specific DIW.

Beyond non-specific and specific DIW, our results demonstrated that mental distress is also significantly related to individuals' specific and non-specific medical costs in the first and second year. Specific costs in the first year were 11.4-times higher for severe cases, compared to no cases. Even in the second year, severe cases showed 6.2-times as many specific costs as no cases. This amounts to an additional average specific cost of 2,073 EUR per person and year for severe cases in the first year and 1,106 EUR per person and year in the second year for the public health care system. The predictive effect of nonspecific costs was considerably smaller, but also significant. Compared to no cases, severe cases averaged 2.7-times the costs in the first and 1.9-times the 
costs in the second year. This amounts to additional average non-specific costs of 3,513 EUR per person and year for severe cases in the first year and 2,922 EUR per person and year in the second year for the public health care system. These results underline the socio-economic burden of mental distress for public health care systems. However, they also show that this burden can be predicted by self-reported mental distress at an early stage, which opens the possibility for early interventions. Although these data represent costs from a German population, these results can be seen as an indicator for other industrialized countries, since both the prevalence of mental disorders (Germany 18\%, EU 17.3\%) and the percentage of direct and indirect medical costs due to mental illness in Germany (Germany $4.8 \%$, EU 4.0\%) are comparable to other EU countries [9].

Most demographic characteristics of our sample showed no consistent effects across the different dependent variables. However, these have been included mainly as control variables to control possible confounding variables. Future studies should specifically focus on these variables to draw reliable conclusions about socio-demographic variables' influence on absence days and medical costs. Only the participants' age showed a consistent pattern with increased nonspecific DIW and non-specific medical costs for both years, but no differences in specific DIW and specific medical costs. Lower education in our sample was significantly related to non-specific DIW. However, on specific DIW, the increase by lower education yielded significance only in the second year. These results are in line with prior studies showing that mental distress (anxiety symptoms), higher age, and lower education emerged as significant predictors of nonspecific DIW [30]. Given these findings, it seems likely that lower educational status and higher age can be considered a risk factor for non-specific DIW. However, their effect on specific DIW or medical costs remains uncertain. Future studies should include large and representative samples to investigate the differential effects of age and education on specific and non-specific DIW and specific and non-specific medical costs.

Contrary to prior studies, in which female gender was found to be a significant predictor of specific DIW [31, 32], our analyses showed no differences of specific DIW between male and female participants. However, a closer look at the descriptive factors shows that the factors from our study (1.57) are comparable to those from previous studies $(1.6)[31,32]$. Therefore, the non-significant differences in DIW depending on the sample characteristics in our study could result from a too-small sample size in the different subgroups, thus limiting the power for individual comparisons. With $89 \%$, the proportion of female participants was considerably high. Interestingly, female participants showed higher specific medical costs in both years. This finding is in line with prior research, indicating a higher prevalence of anxiety and affective mental disorders in female populations [9, 35].

\section{Strengths, Limitations, And Recommendations For Future Research}

Our study's major strengths relate to its longitudinal research design and the analysis of real DIW and medical cost data from a health insurance company in conjunction with psychometrically assessed mental distress from individuals. By including DIW and medical costs in the first and second year, we were able to show that self-reported mental distress was predictive for DIW and medical costs regardless of the DIW and medical costs occurring immediately after the HADS assessment, and this enabled us to show the long-term consequences of severe mental distress. By including specific and non-specific DIW and specific and non-specific costs as dependent variables, we were able to show the importance of mental health for general, occupational functioning and point to the consequences of mental distress for companies and the public health care systems. Furthermore, the available cut-off scores of the HADS to distinguish between no, mild, moderate, and severe cases allowed us to demonstrate clear, practical implications for the consequences of severe mental distress in applied settings. However, this study has some limitations, which should be considered when interpreting the results.

First, we only investigated the main effects of the sample characteristics and mental distress. However, more complex interaction effects between the independent variables are conceivable and should be investigated in future studies using larger sample sizes. Second, although our overall sample size was reasonably large, it does not signify a representative sample of the German population. Thus, some socio-demographic subgroups might be too small, resulting in limited power for examining the relationship between different sample characteristics and DIW and medical costs, respectively (e.g., $\mathrm{n}=11$ participants in the unemployment group). Third, in addition to the sample characteristics analyzed in this study, other variables might impact the relationship between mental distress and DIW, such as the quality of health management in organizations [36], subjectively perceived workplace characteristics (e.g., social support, leadership quality; [37, 38]), or inter-individual differences in psychological conditions, such as self-efficacy or work attitude [39]). In addition, variables should be investigated, influencing the relationship between mental distress and medical costs, such as access to psychotherapy or stigmatization. Finally, we analyzed DIW and medical costs independently of each other. Future studies should investigate how medical costs and DIW are related to each other over time (e.g., whether increased specific medical costs help reduce DIW). Future studies should also systematically investigate how prevention programs for distressed individuals and evidence-based treatments for individuals with mental disorders contribute to saving money by restoring occupational and social functioning.

\section{Implications For Practice}

This study shows the extent to which self-reported mental distress is related to the subsequent inability to work and to medical costs. On an individual level, our results indicate that mental distress affects a person's life after a span of two years by reducing occupational and social functioning. Our results demonstrate the high socio-economic costs of mental distress through productivity losses due to reduced functional levels at the societal level. The results, therefore, suggest that joint efforts should be made to effectively reduce mental distress. Individuals with mild and moderate mental distress who do not yet suffer from a manifested mental illness should be given access to preventive services. Preventive structures should be established within peoples' everyday lives (e.g., at the workplace) to enable low-threshold access [15-16]. Not recognizing mental distress, ignoring it, or not taking effective countermeasures might exacerbate the problem and result in significant negative financial impact. A preventive commitment from employers to the workforce's mental health should ultimately lead to a better working atmosphere, a better quality of life for employees, and an increase in productivity [11].

Individuals with severe mental distress or those with manifested mental disorders should be given rapid access to specialized help in the form of evidencebased psychotherapeutic or psychiatric treatments. Prior studies from the UK have shown that increasing access to psychological therapies would largely pay 
for itself by reducing other depression and anxiety-related public costs (e.g., medical costs and productivity loss) and increasing revenues (e.g., paying taxes [16]). Rapid access to mental health services should be enabled, since the time spent waiting to start psychological treatments was negatively associated with treatment outcome [15]. One best-practice example of how access to psychotherapy can be improved is the English Improving Access to Psychological Therapies (IAPT) service, which delivers psychological therapies recommended by the National Institute for Health and Care Excellence for depression and anxiety disorders to more than 537,000 patients in the UK each year [15]. Evaluation by the IAPT approach has shown that $40.3 \%$ of patients showed reliable recovery, $63.7 \%$ showed a reliable improvement, and $6.6 \%$ showed reliable deterioration [40].

The short processing time of the HADS and the simultaneously good predictive validity regarding the DIW allow for an efficient, cost-effective, and early assessment of the mental distress across different settings. Therefore, it could be used as a suitable screening tool for mental distress to effectively allocate prevention measures in the context of selected or indicated prevention. To improve access to specialized treatments, general practitioners in private practice could use the HADS as a risk-assessment parameter for mental disorders. Since the HADS is suitable for identifying specific mental disorders in physical health settings, it might be advisable to consult an expert (i.e., a psychiatrist or psychotherapist) if conspicuous values of the HADS appear [27].

\section{Conclusion}

In summary, our study demonstrates the extent to which mental distress is associated with reduced occupational and social functioning. Accordingly, mental distress significantly impacts the number of DIW and medical costs for a span of two years following the initial HADS assessment. These results indicate that improving preventive structures for at-risk populations and increasing access to specialized treatments for individuals with mental disorders might reduce individual suffering as well as public costs.

\section{Abbreviations}

DIW = Days of Incapacity to Work

$\mathrm{MC}=$ Medical Costs

HADS = Hospital Anxiety and Depression Scale

EUR $=$ Euro

DALY = Disability Adjusted Life Years

$\mathrm{EU}=$ European Union

US = United States

USD = US Dollar

IAPT = English Improving Access to Psychological Therapies

UK = United Kingdom

DRKS = Deutsches Register Klinischer Studien (German Register of Clinical Studies)

$I C D=$ International Statistical Classification of Diseases and Related Health Problems

\section{Declarations}

\section{Ethics approval and consent to participate}

This study was approved by the ethical review committee at the University of Heidelberg (2013620NMA). Written informed consent to participate in the study was obtained from participants.

\section{Consent for publication}

Not applicable, no individual data.

\section{Availability of data and material}

The datasets generated and/or analyzed during the current study are not publicly available due to the data protection policy from the cooperating insurance fund but are available from the corresponding author on reasonable request (in anonymized form).

\section{Competing interests}

G. Mueller and M. Bombana are employees of the sponsor. The authors declare that the research was conducted in the absence of any commercial or financial relationships that could be construed as a potential conflict of interest.

\section{Funding}


This study was financed by the health insurance fund AOK Baden-Württemberg. The compilation of health care costs directly from the insurance fund's records required a close cooperation throughout all phases of the project. In order to ensure scientific objectivity and simultaneously comply with the data protection policy, the sponsor commissioned an internal research officer (GM) and signed a contractual agreement with the research facility (CIMH Mannheim) that all data may be published regardless of possible positive or negative results.

\section{Authors' contributions}

GM, LL, MBoh and NK designed the study. LL, GM and RV collected the data. GM analyzed the data and discussed the results with RV. MBom and MHG provided statistical advice. GM and RV prepared the first draft of the manuscript. All authors reviewed the manuscript.

\section{Acknowledgements}

Not applicable

\section{References}

1. Spitzer RL, Kroenke K, Linzer M, Hahn SR, Williams JBW, Degruy FV, et al. Health-related quality of life in primary care patients with mental disorders: results from the PRIME-MD 1000 study. JAMA. 1995;274:1511-7.

2. ESEMeD/MHEDEA 2000 Investigators, Alonso J, Angermeyer MC, Bernert S, Bruffaerts R, Brugha TS, et al. Disability and quality of life impact of mental disorders in Europe: results from the European Study of the Epidemiology of Mental Disorders (ESEMeD) project. Acta Psychiatrica Scandinavica. 2004;109:38-46.

3. Statistisches Bundesamt ZB. Krankheitskostenrechnung. www.gbe-bund.de. Accessed 27 Apr 2020.

4. Weltgesundheitsorganisation. Regionalbüro für Europa. Psychische Gesundheit: Herausforderungen annehmen, Lösungen schaffen: Bericht über die Europäische Ministerielle WHO-Konferenz. Kopenhagen: Weltgesundheitsorganisation, Regionalbüro für Europa; 2006.

5. Vos T, Barber RM, Bell B, Bertozzi-Villa A, Biryukov S, Bolliger I, et al. Global, regional, and national incidence, prevalence, and years lived with disability for 301 acute and chronic diseases and injuries in 188 countries, 1990-2013: a systematic analysis for the Global Burden of Disease Study 2013. The Lancet. 2015;386:743-800.

6. Patel V, Saxena S, Lund C, Thornicroft G, Baingana F, Bolton P, et al. The Lancet Commission on global mental health and sustainable development. The Lancet. 2018;392:1553-98. doi:10.1016/S0140-6736(18)31612-X.

7. James SL, Abate D, Abate KH, Abay SM, Abbafati C, Abbasi N, et al. Global, regional, and national incidence, prevalence, and years lived with disability for 354 diseases and injuries for 195 countries and territories, 1990-2017: a systematic analysis for the Global Burden of Disease Study 2017. The Lancet. 2018;392:1789-858.

8. Steel Z, Marnane C, Iranpour C, Chey T, Jackson JW, Patel V, Silove D. The global prevalence of common mental disorders: a systematic review and metaanalysis 1980-2013. Int J Epidemiol. 2014;43:476-93. doi:10.1093/ije/dyu038.

9. Health at a Glance. Europe 2018: OECD; 2018.

10. Bloom DE, Cafiero E, Jané-Llopis E, Abrahams-Gessel S, Bloom LR, Fathima S. The Global economic burden of noncommunicable diseases. Geneva: World Economic Forum; 2011.

11. The Lancet Commission on global mental health and sustainable development. 2018. https://globalmentalhealthcommission.org/wpcontent/uploads/2018/10/Lancet-Commission_policy-brief_MHIN2.pdf.pdf. Accessed 4 Aug 2020.

12. Campion J, Bhui K, Bhugra D. European Psychiatric Association (EPA) guidance on prevention of mental disorders. European Psychiatry. 2012;27:68-80.

13. Kohn R, Saxena S, Levav I, Saraceno B. The treatment gap in mental health care. Bull World Health Organ. 2004;82:858-66.

14. Clark DM, Canvin L, Green J, Layard R, Pilling S, Janecka M. Transparency about the outcomes of mental health services (IAPT approach): an analysis of public data. The Lancet. 2018;391:679-86.

15. Laynard R, Clark D, Knapp M, Mayraz G. Cost-benefit analysis of psychological therapy. Natl Inst Econ Rev. 2007;202:90-8.

16. Clark DM. Realizing the mass public benefit of evidence-based psychological therapies: the IAPT program. Annual Review of Clinical Psychology. 2018;14

17. Lyssenko L, Muller G, Kleindienst N, Schmahl C, Berger M, Eifert G, et al. Life balance- a mindfulness-based mental health promotion program: conceptualization, implementation, compliance and user satisfaction in a field setting. BMC Public Health. 2015;15:740. doi:10.1186/s12889-015-2100-z.

18. Lyssenko L, Müller G, Kleindienst N, Schmahl C, Berger M, Eifert G, et al. Effectiveness of a mindfulness-based mental health promotion program provided by health coaches: a controlled multisite field trial. Psychother Psychosom. 2016;85:375-7.

19. Müller G, Pfinder M, Schmahl C, Bohus M, Lyssenko L. Cost-effectiveness of a mindfulness-based universal mental health promotion program. BMC Public Health. 2019;19.

20. Herrmann-Lingen C, Buss U, Snaith P. Hospital Anxiety and Depression Scale-Deutsche Version (HADS-D): Huber; 2011.

21. Bjelland I, Dahl AA, Haug TT, Neckelmann D. The validity of the Hospital Anxiety and Depression Scale: an updated literature review. J Psychosom Res. 2002;52:69-77.

22. Spinhoven PH, Ormel J, Sloekers PPA, Kempen G, Speckens AEM, van Hemert. A validation study of the Hospital Anxiety and Depression Scale (HADS) in different groups of Dutch subjects. Psychol Med. 1997;27:363-70. 
23. Snaith RP, Zigmond AS. The Hospital Anxiey and Depression Scale with the irritability-depression-anxiety scale and the Leeds Situational Anxiety Scale. Manual: Nfer-Nelson; 1994.

24. Hinz A, Brähler E. Normative values for the Hospital Anxiety and Depression Scale (HADS) in the general German population. J Psychosom Res. $2011 ; 71: 74-8$

25. Geue K, Strauß B, Brähler E. Diagnostische Verfahren in der Psychotherapie: Hogrefe Verlag; 2016.

26. Brennan C, Worrall-Davies A, McMillan D, Gilbody S, House A. The Hospital Anxiety and Depression Scale: a diagnostic meta-analysis of case-finding ability. J Psychosom Res. 2010;69:371-8.

27. Hasan MM, Dunn PK. Two Tweedie distributions that are near-optimal for modelling monthly rainfall in Australia. Int J Climatol. 2011;31:1389-97.

28. König U, Heinzel-Gutenbrunner M, Meinlschmidt G, Maier W, Bachmann CJ. Einfluss des sozioökonomischen Status auf Gesundheitskosten für Kinder und Jugendliche mit Störungen des Sozialverhaltens: Eine Analyse von Routinedaten einer gesetzlichen Krankenversicherung. Bundesgesundheitsblatt Gesundheitsforschung Gesundheitsschutz. 2019;62:1057-66. doi:10.1007/s00103-019-02991-1.

29. Schneider A, Hilbert S, Hamann J, Skadsem S, Glaser J, Löwe B, Bühner M. The implications of psychological symptoms for length of sick leave. Dtsch Arztebl Int. 2017;114:291-7. doi:10.3238/arztebl.2017.0291.

30. Adli M. Psychische Gesundheit und Arbeit: Zahlen, Daten, Fakten. Berlin: MWV Medizinisch Wissenschaftliche Verlagsgesellschaft; 2019.

31. Krenzer K, Psychoreport. 2019. 2019. https://www.dak.de/dak/bundesthemen/dak-psychoreport-2019-dreimal-mehr-fehltage-als-1997-2125486.html.

32. Hannula JA, Lahtela K, Järvikoski A, Salminen K, Mäkelä J. P. Occupational Functioning Scale (OFS)-an instrument for assessment of work ability in psychiatric disorders. Nord J Psychiatry. 2006;60:372-8.

33. Bundesanstalt für Arbeitsschutz und Arbeitsmedizin. Sicherheit und Gesundheit bei der Arbeit 2014. Unfallverhütungsbericht Arbeit. 2014.

34. Seedat S, Scott KM, Angermeyer MC, Berglund P, Bromet EJ, Brugha TS, et al. Cross-national associations between gender and mental disorders in the World Health Organization World Mental Health Surveys. Arch Gen Psychiatry. 2009;66:785-95.

35. Cullen KL, Irvin E, Collie A, Clay F, Gensby U, Jennings PA, et al. Effectiveness of workplace interventions in return-to-work for musculoskeletal, pain-related and mental health conditions: an update of the evidence and messages for practitioners. J Occup Rehabil. 2018;28:1-15.

36. Lysaght RM, Larmour-Trode S. An exploration of social support as a factor in the return-to-work process. Work. 2008;30:255-66.

37. Aas RW, Ellingsen KL, Lindøe P, Möller A. Leadership qualities in the return to work process: a content analysis. J Occup Rehabil. 2008;18:335.

38. Brouwer S, Reneman MF, Bültmann U, Van der Klink, Jac JL, Groothoff JW. A prospective study of return to work across health conditions: perceived work attitude, self-efficacy and perceived social support. J Occup Rehabil. 2010;20:104-12.

39. Gyani A, Shafran R, Layard R, Clark DM. Enhancing recovery rates: lessons from year one of IAPT. Behav Res Ther. 2013;51:597-606.

\section{Tables}




\begin{tabular}{|c|c|c|c|}
\hline & & $\mathrm{N}$ & percent \\
\hline \multirow[t]{2}{*}{ Gender } & female & 2,029 & $88.7 \%$ \\
\hline & male & 258 & $11.3 \%$ \\
\hline \multirow[t]{3}{*}{ Age } & $18-33$ years & 366 & $16.0 \%$ \\
\hline & $34-49$ years & 906 & $39.6 \%$ \\
\hline & $50-65$ years & 1,015 & $44.4 \%$ \\
\hline \multirow[t]{2}{*}{ Marital status } & married & 1,655 & $72.4 \%$ \\
\hline & not married & 632 & $27.6 \%$ \\
\hline \multirow[t]{4}{*}{ Years of school education } & no school-leaving certificate & 57 & $2.5 \%$ \\
\hline & 9 years & 592 & $25.9 \%$ \\
\hline & 10 years & 1,051 & $46.0 \%$ \\
\hline & 13 years (A-Level) & 587 & $25.7 \%$ \\
\hline \multirow[t]{2}{*}{ Employment Status } & employed & 2,276 & $99.5 \%$ \\
\hline & unemployed & 11 & $0.5 \%$ \\
\hline \multirow[t]{4}{*}{ Mental distress category (HADS) } & no case & 1,089 & $47.6 \%$ \\
\hline & mild case & 552 & $24.1 \%$ \\
\hline & moderate case & 538 & $23.5 \%$ \\
\hline & severe case & 108 & $4.7 \%$ \\
\hline
\end{tabular}

Table 2. Results from the generalized linear model to predict the non-specific days of incapacity to work (due to any diagnosis) by self-reported mental distress, controlled for socio-demographic characteristics of the sample 


\begin{tabular}{|c|c|c|c|c|c|c|c|c|c|c|c|c|c|c|c|}
\hline \multirow[b]{3}{*}{ Constant } & & \multicolumn{7}{|c|}{ Non-specific DIW in the first year } & \multicolumn{7}{|c|}{ Non-specific DIW in the second year } \\
\hline & & \multirow[t]{2}{*}{ M } & \multicolumn{2}{|c|}{$95 \% \mathrm{Cl}$} & \multirow{2}{*}{$\begin{array}{l}\operatorname{Exp}(B) \\
6.44\end{array}$} & \multicolumn{2}{|c|}{$95 \% \mathrm{Cl}$} & \multirow{2}{*}{$\begin{array}{l}\begin{array}{l}\mathrm{p}- \\
\text { value }\end{array} \\
< \\
.001\end{array}$} & \multirow[t]{2}{*}{ M } & \multicolumn{2}{|c|}{$95 \% \mathrm{Cl}$} & \multirow{2}{*}{$\begin{array}{l}\operatorname{Exp}(B) \\
6.39\end{array}$} & \multicolumn{2}{|c|}{$95 \% \mathrm{Cl}$} & \multirow{2}{*}{$\begin{array}{l}\begin{array}{l}\mathrm{p}- \\
\text { value }\end{array} \\
< \\
.001\end{array}$} \\
\hline & & & & & & 4.95 & 8.38 & & & & & & 4.85 & 8.41 & \\
\hline \multirow[t]{2}{*}{ Gender } & $\mathrm{male}^{\mathrm{a}}$ & 32.2 & 22.9 & 45.4 & 1.00 & & & & 22.5 & 15.2 & 33.2 & 1.00 & & & \\
\hline & female & 37.8 & 27.8 & 51.6 & 1.17 & 0.97 & 1.42 & .093 & 27.2 & 19.0 & 39.1 & 1.21 & 1.00 & 1.47 & .052 \\
\hline \multirow[t]{3}{*}{ Age groups } & $18-33$ years $^{a}$ & 28.4 & 20.1 & 40.2 & 1.00 & & & & 21.0 & 14.2 & 31.2 & 1.00 & & & \\
\hline & $34-49$ years & 35.0 & 25.4 & 48.2 & 1.23 & 1.03 & 1.48 & .026 & 22.8 & 15.7 & 33.0 & 1.08 & 0.89 & 1.31 & .412 \\
\hline & $50-65$ years & 42.8 & 31.4 & 58.5 & 1.51 & 1.26 & 1.81 & $<.001$ & 31.6 & 22.0 & 45.4 & 1.51 & 1.25 & 1.82 & $<.001$ \\
\hline \multirow[t]{2}{*}{ Marital status } & married $^{\mathrm{a}}$ & 33.0 & 24.1 & 45.1 & 1.00 & & & & 23.2 & 16.2 & 33.4 & 1.00 & & & \\
\hline & not married & 37.0 & 26.8 & 51.1 & 1.12 & 0.99 & 1.27 & .072 & 26.3 & 18.1 & 38.2 & 1.13 & 0.99 & 1.29 & .065 \\
\hline \multirow[t]{4}{*}{$\begin{array}{l}\text { Years of school } \\
\text { education }\end{array}$} & $\begin{array}{l}13 \text { years (A- } \\
\text { Level) }\end{array}$ & 25.1 & 18.1 & 34.9 & 1.00 & & & & 16.5 & 11.3 & 24.2 & 1.00 & & & \\
\hline & 10 years & 30.3 & 22.1 & 41.5 & 1.21 & 1.04 & 1.40 & .016 & 20.7 & 14.3 & 30.1 & 1.23 & 1.07 & 1.47 & .005 \\
\hline & 9 years & 37.9 & 27.5 & 52.2 & 1.51 & 1.23 & 1.79 & $<.001$ & 29.6 & 20.3 & 43.0 & 1.79 & 1.50 & 2.13 & $<.001$ \\
\hline & $\begin{array}{l}\text { no school- } \\
\text { leaving } \\
\text { certificate }^{a}\end{array}$ & 51.7 & 34.2 & 78.1 & 2.06 & 1.50 & 2.83 & $<.001$ & 36.9 & 23.6 & 57.7 & 2.23 & 1.59 & 3.13 & $<.001$ \\
\hline \multirow{2}{*}{$\begin{array}{l}\text { Employment } \\
\text { Status }\end{array}$} & employed $^{a}$ & 27.9 & 24.6 & 31.5 & 1.00 & & & & 24.9 & 21.9 & 28.3 & 1.00 & & & \\
\hline & unemployed & 43.8 & 24.0 & 79.9 & 1.57 & 0.86 & 2.87 & .143 & 24.6 & 12.1 & 49.8 & 0.99 & 0.48 & 2.02 & .973 \\
\hline \multirow[t]{4}{*}{$\begin{array}{l}\text { Mental distress } \\
\text { category (HADS) }\end{array}$} & no case $e^{a}$ & 15.8 & 11.4 & 22.1 & 1.00 & & & & 13.1 & 9.0 & 19.1 & 1.00 & & & \\
\hline & mild case & 25.8 & 18.4 & 36.2 & 1.63 & 1.40 & 1.90 & $<.001$ & 19.1 & 13.0 & 28.0 & 1.46 & 1.25 & 1.70 & $<.001$ \\
\hline & moderate case & 44.7 & 32.2 & 61.9 & 2.82 & 2.45 & 3.25 & $<.001$ & 30.6 & 21.1 & 44.3 & 2.34 & 2.02 & 2.71 & $<.001$ \\
\hline & severe case & 81.4 & 58.0 & 114.3 & 5.14 & 4.11 & 6.41 & $<.001$ & 48.9 & 32.7 & 73.0 & 3.73 & 2.95 & 4.72 & $<.001$ \\
\hline
\end{tabular}

Note. $\mathrm{N}=2.287$. t0 = assessment of predictor variables. $\mathrm{M}_{\mathrm{DIW}}=$ Mean days of incapacity to work. $\mathrm{Cl}=95 \%$ confidence interval. $\mathrm{HADS}=\mathrm{Hospital}$ Anxiety and Depression Scale. $a=$ reference category. Method = log-link function, Tweedie-distribution of residuals.

Table 3. Results from the generalized linear model to predict the specific days of incapacity to work (due to mental illness) by self-reported mental distress, controlled for socio-demographic characteristics of the sample 


\begin{tabular}{|c|c|c|c|c|c|c|c|c|c|c|c|c|c|c|c|}
\hline \multirow[b]{3}{*}{ Constant } & & \multicolumn{7}{|c|}{ Specific DIW in the first year } & \multicolumn{7}{|c|}{ Specific DIW in the second year } \\
\hline & & \multirow[t]{2}{*}{ M } & \multicolumn{2}{|c|}{$95 \% \mathrm{Cl}$} & \multirow{2}{*}{$\begin{array}{l}\operatorname{Exp}(\mathrm{B}) \\
0.78\end{array}$} & \multicolumn{2}{|l|}{$95 \% \mathrm{Cl}$} & \multirow{2}{*}{$\begin{array}{l}\begin{array}{l}\mathrm{p}- \\
\text { value }\end{array} \\
.533\end{array}$} & \multirow[t]{2}{*}{ M } & \multicolumn{2}{|c|}{$95 \% \mathrm{Cl}$} & \multirow{2}{*}{$\begin{array}{l}\operatorname{Exp}(\mathrm{B}) \\
1.25\end{array}$} & \multicolumn{2}{|c|}{$95 \% \mathrm{Cl}$} & \multirow{2}{*}{$\begin{array}{l}\begin{array}{l}\mathrm{p}- \\
\text { value }\end{array} \\
.567\end{array}$} \\
\hline & & & & & & 0.36 & 1.69 & & & & & & 0.58 & 2.69 & \\
\hline \multirow[t]{2}{*}{ Gender } & male $^{\mathrm{a}}$ & 11.2 & 5.1 & 24.5 & 1.00 & & & & 10.2 & 4.4 & 23.3 & 1.00 & & & \\
\hline & female & 17.5 & 9.1 & 33.9 & 1.57 & 0.91 & 2.69 & .373 & 15.1 & 7.4 & 30.9 & 1.48 & 0.87 & 2.52 & .147 \\
\hline \multirow[t]{3}{*}{ Age groups } & $18-33$ years $^{a}$ & 11.1 & 5.0 & 24.5 & 1.00 & & & & 11.3 & 4.9 & 26.1 & 1.00 & & & \\
\hline & $34-49$ years & 16.3 & 8.1 & 32.5 & 1.47 & 0.89 & 2.41 & .129 & 11.5 & 5.4 & 24.5 & 1.01 & 0.62 & 1.65 & .964 \\
\hline & $50-65$ years & 15.2 & 7.7 & 29.7 & 1.37 & 0.83 & 2.26 & .221 & 14.6 & 7.1 & 30.0 & 1.29 & 0.79 & 2.09 & .309 \\
\hline \multirow[t]{2}{*}{ Marital status } & married $^{\mathrm{a}}$ & 14.2 & 7.2 & 28.1 & 1.00 & & & & 11.2 & 5.4 & 23.4 & 1.00 & & & \\
\hline & not married & 13.7 & 6.8 & 27.9 & 0.96 & 0.68 & 1.36 & .835 & 13.6 & 6.4 & 29.2 & 1.22 & 0.87 & 1.70 & .258 \\
\hline \multirow[t]{4}{*}{$\begin{array}{l}\text { Years of } \\
\text { school } \\
\text { education }\end{array}$} & $\begin{array}{l}13 \text { years (A- } \\
\text { Level) }^{a}\end{array}$ & 10.8 & 5.2 & 22.6 & 1.00 & & & & 7.3 & 3.3 & 16.1 & 1.00 & & & \\
\hline & 10 years & 13.1 & 6.7 & 25.8 & 1.21 & 0.80 & 1.83 & .360 & 10.2 & 4.8 & 21.7 & 1.41 & 0.92 & 2.15 & .114 \\
\hline & 9 years & 12.1 & 6.0 & 24.6 & 1.12 & 0.70 & 1.79 & .636 & 13.1 & 6.0 & 28.4 & 1.80 & 1.13 & 2.85 & .013 \\
\hline & $\begin{array}{l}\text { no school- } \\
\text { leaving } \\
\text { certificate }^{a}\end{array}$ & 22.1 & 8.7 & 56.5 & 2.04 & 0.93 & 4.48 & .074 & 24.2 & 9.5 & 61.6 & 3.32 & 1.51 & 7.28 & .003 \\
\hline \multirow{2}{*}{$\begin{array}{l}\text { Employment } \\
\text { Status }\end{array}$} & employed $^{\mathrm{a}}$ & 8.4 & 6.0 & 11.7 & 1.00 & & & & 9.0 & 6.5 & 12.5 & 1.00 & & & \\
\hline & unemployed & 23.4 & 6.6 & 82.5 & 2.80 & 0.80 & 9.86 & .108 & 17.0 & 4.2 & 68.0 & 1.88 & 0.46 & 7.59 & .377 \\
\hline \multirow{4}{*}{$\begin{array}{l}\text { Mental distress } \\
\text { category } \\
\text { (HADS) }\end{array}$} & no case ${ }^{a}$ & 2.6 & 1.2 & 5.6 & 1.00 & & & & 4.3 & 2.0 & 9.3 & 1.00 & & & \\
\hline & mild case & 7.4 & 3.5 & 15.8 & 2.83 & 1.78 & 4.49 & $<.001$ & 6.2 & 2.8 & 14.0 & 1.46 & 0.94 & 2.28 & .095 \\
\hline & $\begin{array}{l}\text { moderate } \\
\text { case }\end{array}$ & 27.5 & 13.6 & 55.9 & 10.50 & 7.04 & 15.67 & $\begin{array}{l}< \\
.001\end{array}$ & 20.1 & 9.5 & 42.4 & 4.71 & 3.21 & 6.90 & $\begin{array}{l}< \\
.001\end{array}$ \\
\hline & severe case & 71.5 & 34.7 & 147.1 & 27.26 & 15.79 & 47.07 & $<.001$ & 43.9 & 19.5 & 99.0 & 10.29 & 5.97 & 17.72 & $<.001$ \\
\hline
\end{tabular}

Note. $\mathrm{N}=2.287 . \mathrm{t0}=$ assessment of predictor variables. $\mathrm{M}_{\mathrm{DIW}}=$ Mean days of incapacity to work. $\mathrm{Cl}=95 \%$ confidence interval. $\mathrm{HADS}=\mathrm{Hospital}$ Anxiety and Depression Scale. $a$ = reference category. Method $=$ log-link function, Tweedie-distribution of residuals.

Table 4. Results from the generalized linear model to predict the direct non-specific medical costs by self-reported mental distress, controlled for sociodemographic characteristics of the sample 


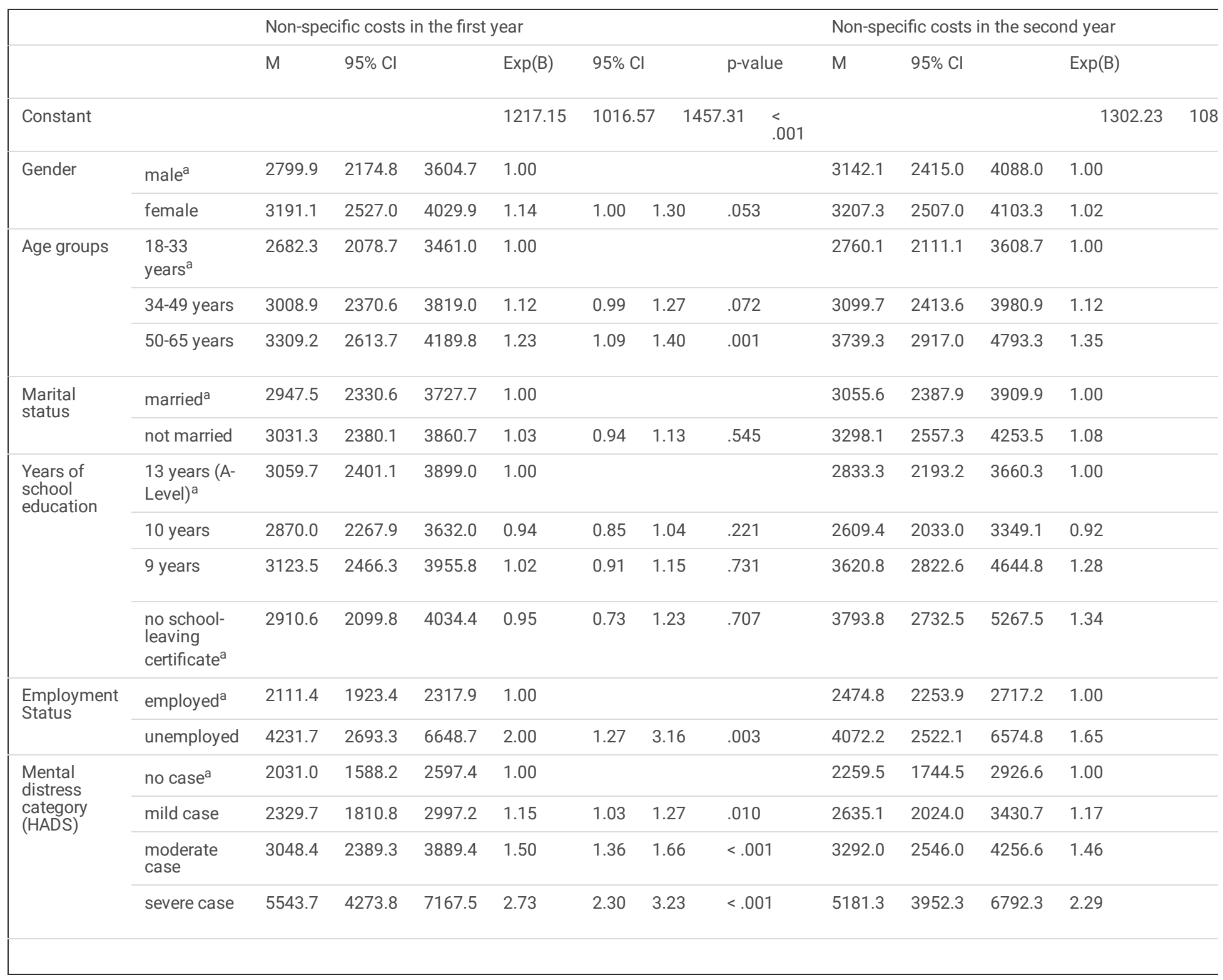

Note. $\mathrm{N}=2.287 . \mathrm{t} 0=$ assessment of predictor variables. $\mathrm{M}=$ Mean non-specific direct costs per person and year. $\mathrm{Cl}=95 \%$ confidence interval. $\mathrm{HADS}=\mathrm{Hospital}$ Anxiety and Depression Scale. $a=$ reference category. Method = log-link function, Tweedie-distribution of residuals.

Table 5. Results from the generalized linear model to predict the direct specific medical costs by self-reported mental distress, controlled for sociodemographic characteristics of the sample 


\begin{tabular}{|c|c|c|c|c|c|c|c|c|c|c|c|c|c|c|}
\hline & & \multicolumn{7}{|c|}{ Specific costs in the first year } & \multicolumn{6}{|c|}{ Specific costs in the second year } \\
\hline & & M & $95 \% \mathrm{Cl}$ & & $\operatorname{Exp}(B)$ & $95 \% \mathrm{Cl}$ & & $\begin{array}{l}\mathrm{p}- \\
\text { value }\end{array}$ & M & $95 \% \mathrm{Cl}$ & & $\operatorname{Exp}(B)$ & $95 \% \mathrm{Cl}$ & \\
\hline Constant & & & & & 93.72 & 67.94 & 129.28 & $\begin{array}{l}< \\
.001\end{array}$ & & & & 132.74 & 96.86 & 181.9 \\
\hline \multirow[t]{2}{*}{ Gender } & $\mathrm{male}^{\mathrm{a}}$ & 595.4 & 395.2 & 897.1 & 1.00 & & & & 397.7 & 259.9 & 608.6 & 1.00 & & \\
\hline & female & 721.4 & 395.2 & 897.1 & 1.21 & 0.96 & 1.53 & .107 & 564.9 & 384.7 & 608.6 & 1.42 & 1.12 & 1.80 \\
\hline \multirow[t]{3}{*}{ Age groups } & $\begin{array}{l}18-33 \\
\text { years }^{\mathrm{a}}\end{array}$ & 687.6 & 458.6 & 1030.8 & 1.00 & & & & 464.9 & 304.7 & 709.4 & 1.00 & & \\
\hline & $34-49$ years & 641.7 & 439.5 & 937.0 & 0.93 & 0.76 & 1.15 & .515 & 444.9 & 298.7 & 662.6 & 0.96 & 0.78 & 1.17 \\
\hline & $50-65$ years & 638.0 & 443.2 & 918.6 & 0.93 & 0.75 & 1.14 & .484 & 514.8 & 349.6 & 758.1 & 1.11 & 0.90 & 1.36 \\
\hline \multirow{2}{*}{$\begin{array}{l}\text { Marital } \\
\text { status }\end{array}$} & married $^{\mathrm{a}}$ & 531.9 & 367.8 & 769.2 & 1.00 & & & & 414.7 & 280.7 & 612.7 & 1.00 & & \\
\hline & not married & 807.5 & 552.8 & 1179.6 & 1.52 & 1.31 & 1.76 & $\begin{array}{l}< \\
.001\end{array}$ & 541.7 & 363.4 & 807.5 & 1.31 & 1.13 & 1.52 \\
\hline \multirow[t]{4}{*}{$\begin{array}{l}\text { Years of } \\
\text { school } \\
\text { education }\end{array}$} & 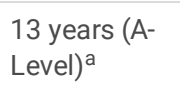 & 492.3 & 334.1 & 725.4 & 1.00 & & & & 474.3 & 315.0 & 714.1 & 1.00 & & \\
\hline & 10 years & 648.7 & 449.0 & 937.3 & 1.89 & 1.04 & 1.40 & .001 & 487.7 & 328.0 & 725.1 & 1.03 & 0.87 & 1.22 \\
\hline & 9 years & 619.4 & 423.4 & 906.2 & 1.26 & 1.23 & 1.79 & .029 & 541.4 & 360.9 & 812.2 & 1.14 & 0.94 & 1.39 \\
\hline & $\begin{array}{l}\text { no school- } \\
\text { leaving } \\
\text { certificate }^{a}\end{array}$ & 932.6 & 573.7 & 1516.1 & 1.32 & 1.10 & 1.58 & .003 & 403.0 & 238.8 & 680.2 & 0.85 & 0.55 & 1.31 \\
\hline \multirow[t]{2}{*}{$\begin{array}{l}\text { Employment } \\
\text { Status }\end{array}$} & employed ${ }^{a}$ & 531.1 & 458.9 & 614.7 & 1.00 & & & & 409.7 & 350.6 & 478.7 & 1.00 & & \\
\hline & unemployed & 808.7 & 402.3 & 1625.8 & 1.52 & 0.76 & 3.05 & .234 & 548.4 & 259.3 & 1159.7 & 1.34 & 0.63 & 2.85 \\
\hline \multirow{4}{*}{$\begin{array}{l}\text { Mental } \\
\text { distress } \\
\text { category } \\
\text { (HADS) }\end{array}$} & no case ${ }^{a}$ & 199.0 & 134.8 & 293.9 & 1.00 & & & & 213.1 & 142.2 & 319.5 & 1.00 & & \\
\hline & mild case & 433.6 & 291.8 & 644.3 & 2.18 & 1.80 & 2.64 & $\begin{array}{l}< \\
.001\end{array}$ & 271.6 & 179.0 & 412.2 & 1.27 & 1.06 & 1.53 \\
\hline & $\begin{array}{l}\text { moderate } \\
\text { case }\end{array}$ & 940.9 & 647.1 & 1368.0 & 4.73 & 3.97 & 5.63 & $<$. & 661.1 & 445.5 & 980.9 & 3.10 & 2.63 & 3.66 \\
\hline & severe case & 2272.3 & 1521.0 & 3394.6 & 11.42 & 8.90 & 14.66 & $\begin{array}{l}< \\
.001\end{array}$ & 1318.9 & 858.7 & 2026.0 & 6.19 & 4.79 & 7.99 \\
\hline
\end{tabular}

Note. $\mathrm{N}=2.287 . \mathrm{t} 0=$ assessment of predictor variables. $\mathrm{M}=$ Mean specific direct costs per person and year. $\mathrm{Cl}=95 \%$ confidence interval. $\mathrm{HADS}=\mathrm{Hospital}$ Anxiety and Depression Scale. $\mathrm{a}=$ reference category. Method $=$ log-link function, Tweedie-distribution of residuals.

\section{Figures}




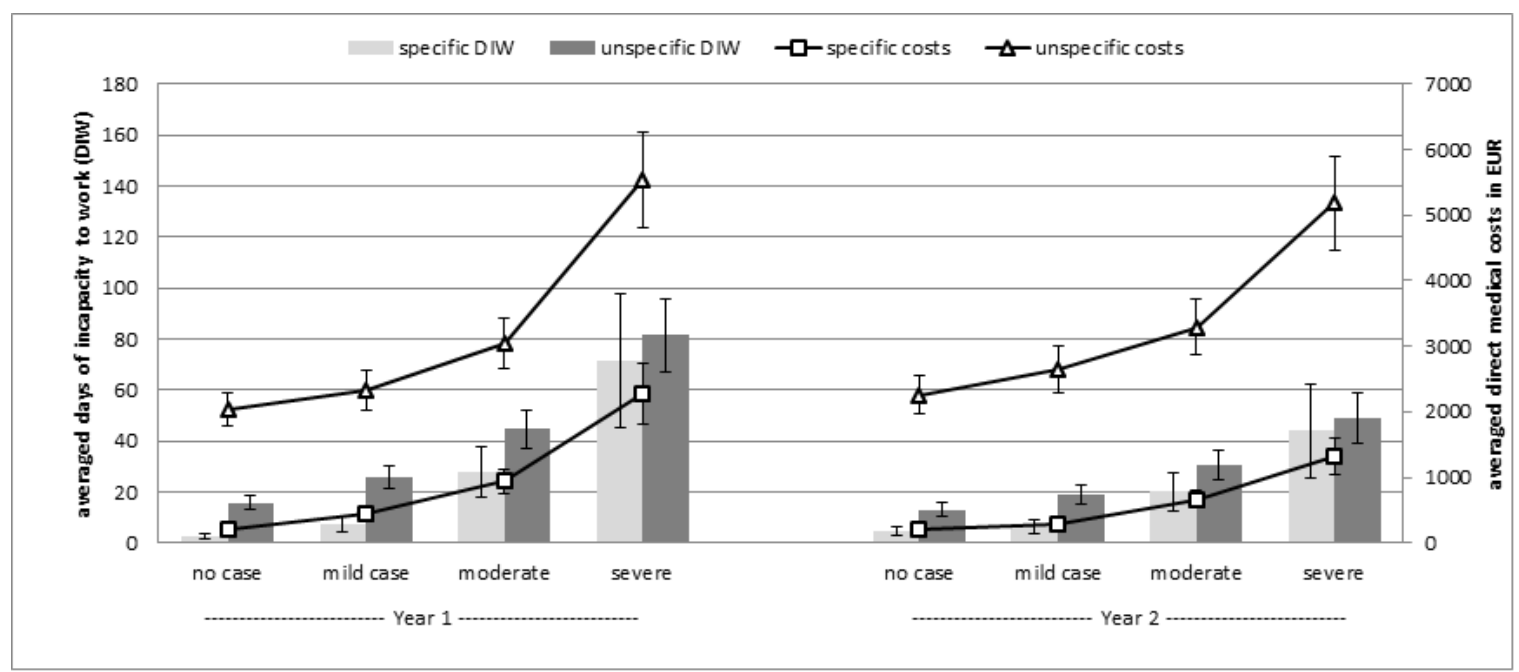

Figure 1

Mean scores of specific and non-specific days of incapacity to work (DIW) on the left y-axis and specific and non-specific medical costs (MC) on the right $y$ axis in the first and second year after HADS assessment, depending on the HADS severity score. Specific = DIW or MC due to mental illness. Non-specific = DIW or MC due to all diagnoses. Results are controlled for age, gender, marital status, education, and employment status. Error bars represent standard errors.

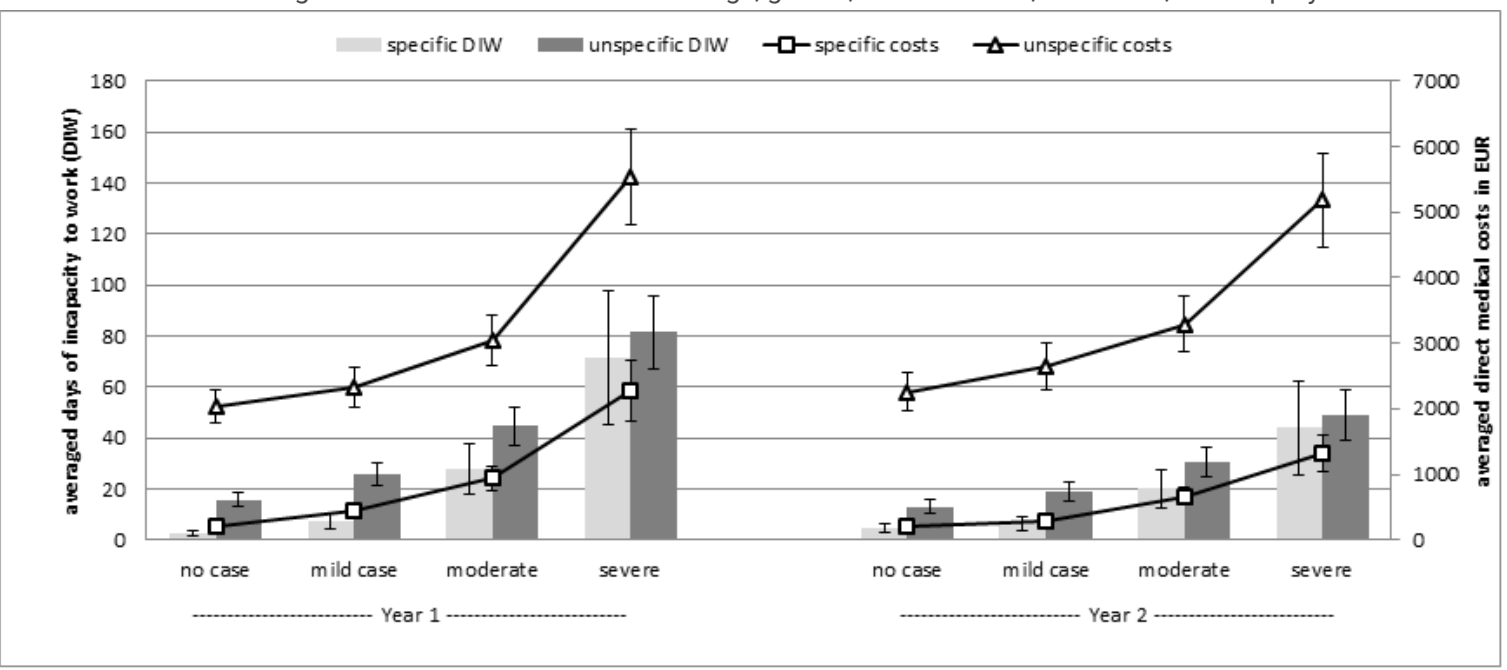

\section{Figure 1}

Mean scores of specific and non-specific days of incapacity to work (DIW) on the left y-axis and specific and non-specific medical costs (MC) on the right $y$ axis in the first and second year after HADS assessment, depending on the HADS severity score. Specific = DIW or MC due to mental illness. Non-specific = DIW or MC due to all diagnoses. Results are controlled for age, gender, marital status, education, and employment status. Error bars represent standard errors. 